\title{
Keunikan Bali dalam Pariwisata Yoga
}

\author{
I Gede Sutarya \\ Email: sutarya@yahoo.com \\ Jurusan Pariwisata Budaya, Fakultas Dharma Duta, IHDN Denpasar \\ Jurnal Pariwisata Budaya Volume 4, Nomer 1, Maret Tahun 2019
}

\begin{abstract}
Abstrak
Pariwisata yoga berkembang di Bali, selain di tempat kelahirannya yoga di India. Pencarian wisman terhadap yoga ke Bali mulai sejak tahun 1970-an dengan membawa guru yoga sendiri. Pada tahun 1980-an, guru-guru yoga lokal mulai terserap menjadi guru yoga untuk wisman. Pencarian wisman terhadap yoga ke Bali menimbulkan masalah penelitian tentang potensi, keunikan dan pengembangan produk yoga. Pertanyaan penelitian ini dibahas dengan teori motivasi, teori produk planning dan teori kepuasan. Data dikumpulkan dengan wawancara mendalam dan kuesioner. Data yang dikumpulkan ini dianalisis secara kualitatif. Hasil penelitian menunjukkan bahwa Bali memiliki potensi yoga yang berkembang pada keunikannya yang berbasis budaya dan etnik Bali. Kepuasan wisman terhadap produk yoga di Bali tertinggi terletak pada budaya dan etnik. Karena itu, pengembangan produk yoga di Bali harus berbasis kepada budaya dan etnik Bali sehingga bisa menjadi daya tarik wisman ke Bali. Daya tarik yang berupa keunikan budaya dan etnik ini menjadi pembeda daripada pariwisata yoga di Bali, dengan pariwisata yoga di tempat-tempat lainnya di dunia.
\end{abstract}

Kata Kunci: Pariwisata Yoga, Keunikan, Pengembangan Produk

Abstract

Yoga tourism is developing in Bali, besides in the place of birth of yoga in India. The search for foreign tourists from yoga to Bali began in the 1970s by bringing yoga teachers themselves. In the 1980s, local yoga teachers began to be absorbed into yoga teachers for foreign tourists. The search for foreign tourists for yoga to Bali raises problems with research on the potential, uniqueness and development of yoga products. This research question is discussed with motivation theory, product theory planning and satisfaction theory. Data was collected by in-depth interviews and questionnaires. The data collected is analyzed qualitatively. The results of the study show that Bali has a yoga potential that develops in its unique culture and ethnicity based on Bali. The highest satisfaction of foreign tourists towards yoga products in Bali lies in culture and ethnicity. Therefore, the development of yoga products in Bali must be based on Balinese culture and ethnicity so that it can become a tourist attraction to Bali. The attraction in the form of cultural and ethnic uniqueness is a differentiator compared to yoga tourism in Bali, with yoga tourism in other places in the world. 
Keywords: Yoga Tourism, Uniqueness, Product Development

\section{Pendahuluan}

Yoga adalah daya tarik pariwisata di dunia, sehingga India dan Bali menjadi tujuan pariwisata yoga. Destinasi yoga di India dan Bali muncul sebagai akibat perkembangan yoga di Eropa dan Amerika yang disebabkan banyaknya guru-guru yoga dari India yang mengajarkan yoga ke Eropa dan Amerika dari sekitar tahun 1960an 9 (Ramstedt, 2008). Perkembangan yoga ini membangun berbagai fasilitas yoga di Eropa dan Amerika. Lalonde (2007) melaporkan berbagai fasilitas yoga di Kanada dan Eropa yaitu eco yoga retreat, ashram, spiritual retreat centre, guest house yoga, hotel garden yoga, pastoral yoga dan professional yoga. Rossin (2006:116) memperkirakan praktisi yoga di Amerika sekitar 15 juta, sehingga hampir seluruh kota di Amerika Serikat memiliki studio yoga.

Penelitian di Amerika menunjukkan bahwa para praktisi yoga memiliki keinginan untuk melakukan kunjungan wisata ke India sebagai pusat yoga (Rossin, 2006:116). Karena itu, studio-studio di Amerika memberikan kontribusi bagi kunjungan wisatawan ke pusat-pusat yoga di India. Sutarya (2018) menyatakan bahwa Bali juga menjadi destinasi pariwisata yoga, karena Bali juga memiliki keotentikan sebagai pusat yoga di mana Bali merupakan pewaris kebudayaan Hindu yang di dalamnya terdapat yoga.

India memiliki pusat-pusat yoga yang terkenal seperti Rsikesh, Bangalore dan kota-kota lainnya, tetapi wisatawan juga mencari yoga ke Bali. Pencarian yoga ke Bali sudah berlangsung sejak tahun 1970-an dengan membawa guru-guru yoga sendiri dari negara wisman. Tahun 1978, Ketut Arsana mendapatkan kesempatan menjadi guru yoga lokal Bali untuk wisman, sehingga ia mendirikan Body Work and Meditation tahun 1980. Guru-guru yoga lainnya seperti Kembar Madrawan dan Sumantra mendapatkan peluang tahun 1990-an. Kunjungan wisman ke pusat-pusat yoga di Ubud pun meningkat mulai tahun 2000-an (Sutarya, 2016).

Kedatangan wisman ke Bali merupakan suatu kekhususan bagi Bali, sebab umumnya masyarakat mengenal India sebagai pusat yoga dunia. Karena itu, kesenjangan antara sesuatu yang ideal dengan kenyataan ini menimbulkan pertanyaan penelitian tentang potensi, keunikan dan pengembangan yoga di Bali. Pertanyaan penelitian ini akan dijawab dengan menggunakan teori motivasi, teori produk planning dan teori kepuasan. Penelitian ini adalah penelitian kualitatif, dengan pengumpulan data melalui studi pustaka, observasi dan wawancara. Wawancara dilakukan secara mendalam dan menggunakan kuesioner. Data tersebut dianalisis secara kualitatif dengan mengorganisasikan data, pengkategorian, menghubungkan antar berbagai kategori dan penarikan kesimpulan.

\section{Pembahasan}


Pada awalnya sekitar tahun 1970-an, Bali dipandang sebagai tempat yang baik untuk beryoga sehingga wisatawan membawa guru-guru yoga ke Bali, tetapi kemudian Bali ternyata memiliki pengetahuan yoga yang berbeda dengan yoga pada umumnya. Pengetahuan yoga di Bali itu berasal dari teks-teks kuno yoga yang berada di Indonesia. Teks-teks tersebut bersumber dari India, tetapi dikembangkan di Nusantara termasuk Bali. Karena itu, potensi yoga di Bali adalah potensi yang berada dalam teks-teks kuno Nusantara yang dikembangkan di Bali.

Potensi-potensi ini dikembangkan menjadi keunikan. Keunikan dari teks-teks yoga di Bali itu adalah tidak membicarakan tentang asana-asana. Teks-teks seperti Sanghyang Kamahayanikan, Tatwajnana, dan Wrespatitatwa hanya membahas tentang yama, nyama (yang disebut dengan dasa sila atau sepuluh pengendalian diri), pranayama (pengaturan napas) dan konsentrasi. Asana-asana yang berkembang di Bali pada era modern adalah berasal dari pengaruh India modern seperti teks Aji Sankya yang terbit tahun 1947 dan tulisan Rsi Ananda Kusuma yang terbit tahun 1960 (Acri, 2013:82).

Keunikan di dalam teks ini membangun etnisitas yoga Bali yang menjadi daya tarik pariwisata yoga di Bali. Keunikan ini yang dikembangkan Guru Made Sumantra menjadi Markendya Yoga pada tahun 1995. Markendya digunakan sebagai simbol guru pertama asal India yang mengajarkan yoga ke Bali, sedangkan latihan-latihannya adalah asana-asana yang umum dengan beberapa kreativitas. Keunikan yang lain dikembangkan Pasraman Ratu Bagus yang menggunakan teknik pernapasan (pranayama) Hanuman. Teknik pernapasan ini diklaim sebagai kekhasan Pasraman Ratu Bagus (Sutarya, 2018:36).

Keunikan-keunikan ini adalah hal-hal yang baru dalam yoga. Wisatawan mengunjungi destinasi apa pun termasuk yoga dengan dorongan dari dalam yang disebut dengan motivasi. Maslow (Schiffman dan Kanuk, 2008:90) menyatakan dorongan yang paling dasar manusia adalah dorongan fisik, kemudian rasa aman, sosial, penghargaan dan aktualisasi diri. Wisman mencari yoga ke Bali karena dorongan-dorongan tersebut, mulai dari fisik (menjadi guru yoga), rasa aman (healing), sosial (bertemu dengan ahli yoga), penghargaan (mengembangkan diri) dan aktualisasi diri (mengembangkan keunikan pengetahuan yoga).

Berdasarkan penelitian (Sutarya, 2018) budaya, etnik dan lingkungan merupakan daya tarik yang paling besar dari yoga di Bali. Karena itu, pencarian tentang kebaruan adalah dorongan wisman. Dorongan mencari kebaruan ini adalah dorongan untuk pengembangan diri, yang tergolong sebagai dorongan untuk mendapatkan penghargaan dan aktualisasi diri. Wisman ingin mendapatkan sesuatu yang berbeda dari yoga-yoga yang sudah didapatkan sebelumnya dari guru-guru India.

Sesuatu yang berbeda itu adalah budaya, etnik dan lingkungan Bali. Perbedaan budaya Bali itu terletak pada ritualnya. Karena itu, yoga-yoga di Bali hampir semuanya memberikan sentuhan budaya, seperti canang sari. Ketut Arsana dari Ashram Munivara, bahkan mengembangkan ritual khusus setiap kliwon, yang berisi ritual, nyanyian dan meditasi. Ashram Ratu Bagus mengembangkan teknik khusus pranayama dan gerakan seperti kerauhan (trance) di Bali. 
Budaya, etnik dan lingkungan ini adalah pembangun perbedaan (differentitiation) dalam pembangunan produk yoga di Bali. Dalam pengembangan produk, pembeda itu menjadi sangat penting. Dalam produk yoga, core produknya pasti sama di seluruh dunia yaitu sehat jasmani dan rohani, tangible produknya adalah latihan-latihan dan augmented produknya adalah bentuk-bentuk pelayanan yang berbeda-beda. Dalam pengembangan produk, pembedaan hanya bisa dibangun pada augmented produk, yaitu membangun pelayanan yang bernuansa Bali.

Pelayanan yang bernuansa Bali itu adalah budaya, etnisitas dan lingkungan yang khas. Dalam konteks budaya, ritual adalah pembedanya. Dalam etnisitas, perlakuan guru-guru yoga Bali yang khas adalah pembedanya dan alam Bali merupakan lingkungan yang khas untuk yoga. Berdasarkan penelitian (Sutarya, 2018:57) yang dilakukan di Ubud dan Sanur terhadap 52 wisman, kepuasan wisman tertinggi pada pariwisata yoga terjadi terhadap budaya $(4,71)$, kemudian lingkungan $(4,63)$ dan etnik $(4,54)$. Karena itu, budaya adalah pembeda yang bisa dikembangkan berdasarkan potensi dan tingkat kepuasan wisman.

\section{Tabel 1}

\section{Tingkat Kepuasan Wisman terhadap Yoga di Bali}

\begin{tabular}{ll|r|r|r|r} 
& $\mathrm{N}$ & \multicolumn{1}{c}{ Minimum } & Maximum & Mean & Std. Deviation \\
\hline Attentions & 52 & 1 & 5 & 4.35 & .861 \\
\hline Performances & 52 & 1 & 5 & 4.42 & .723 \\
\hline Road & 52 & 2 & 5 & 3.88 & .758 \\
\hline FO & 52 & 2 & 5 & 4.31 & .729 \\
\hline Facilities & 52 & 2 & 5 & 4.21 & .776 \\
\hline Etnic & 52 & 2 & 5 & 4.54 & .641 \\
\hline Culture & 52 & 1 & 5 & 4.71 & .667 \\
\hline Ennvironment & 52 & 1 & 5 & 4.63 & .715 \\
\hline
\end{tabular}

Sumber: Hasil Penelitian (Sutarya, 2018)

Eksplorasi tentang potensi dan kepuasan wisman ini membangun pengembangan produk yoga di Bali yang harus berbasiskan budaya. Pengembangan produk yang dilakukan Sumantra dengan Markendya Yoga, Arsana dengan ritual setiap kliwon, dan Pasraman Ratu Bagus dengan teknik pernapasan Hanuman adalah produkproduk yang berbasiskan budaya lokal dalam yoga. Usaha-usaha sejenis harus diikuti dengan berbagai pendekatan. Dalam yoga modern seperti yang dilakukan Kembar Madrawan, budaya dan keunikannya dikembangkan melalui kreativitas gerakan yoga dengan mengadopsi beberapa gerakan tari Bali.

Pengembangan produk yoga di Bali, dapat dikategorikan menjadi tiga bagian yaitu Yoga Bali Tradisi, Yoga Bali Modern dan Yoga Kreasi. Yoga Bali Tradisi dikembangkan Pasraman Ratu Bagus dengan teknik pranayama lokal Bali yang disebut Hanuman. Yoga Bali Modern dikembangkan Sumantra melalui Markendya Yoga yang mengembangkan asana-asana modern dengan perpaduan tradisi Bali. Yoga kreasi 
dikembangkan dengan melakukan kolaborasi jaringan yoga dunia. Pengembangan yoga ini terkonsentrasi di Kawasan Pariwisata Ubud (Sutarya, 2018:37).

Pengembangan produk yoga dalam tiga kategori tersebut menggunakan budaya dan etnik sebagai pembeda. Karena itu, pelayanan-pelayanan yang berdemensi budaya dan etnik menjadi basis daripada pelayanan-pelayanan tambahan yang diberikan. Pelayanan-pelayanan tersebut berupa ritual dan teknik khusus yang bernuansa lokal. Pelayanan khusus tersebut ditambahkan dengan deskripsi tentang sejarah yoga di Bali yang panjang dari zaman mitos Rsi Markendya dengan berbagai peninggalannya di Bali yang berupa pura-pura kuno.

Produk yoga di Bali yang menawarkan keunikannya ini berbeda dengan produk-produk pariwisata yoga di berbagai negara. India menawarkan keasliannya sebagai tempat lahirnya yoga (Maddox, 2015), sedangkan negara-negara Eropa dan Amerika menawarkan berbagai fasilitas modern untuk latihan yoga (Lalonde, 2012). Bali adalah bukan tempat kelahiran yoga, tetapi yoga telah tumbuh dan berkembang di Bali sejak berkembangnya Hindu dan Buddha di Indonesia pada abad ke-10 Masehi, walau pun teks tertuanya yakni Dharma Patanjala ditemukan dari abad ke-15 Masehi (Acri, 2013:72). Perkembangan yoga yang begitu lama di Bali ini memunculkan keunikan budaya dan etnik yang menjadi pembeda yoga di Bali dengan di tempattempat lainnya. Pembeda ini yang mencirikan yoga di Bali. 

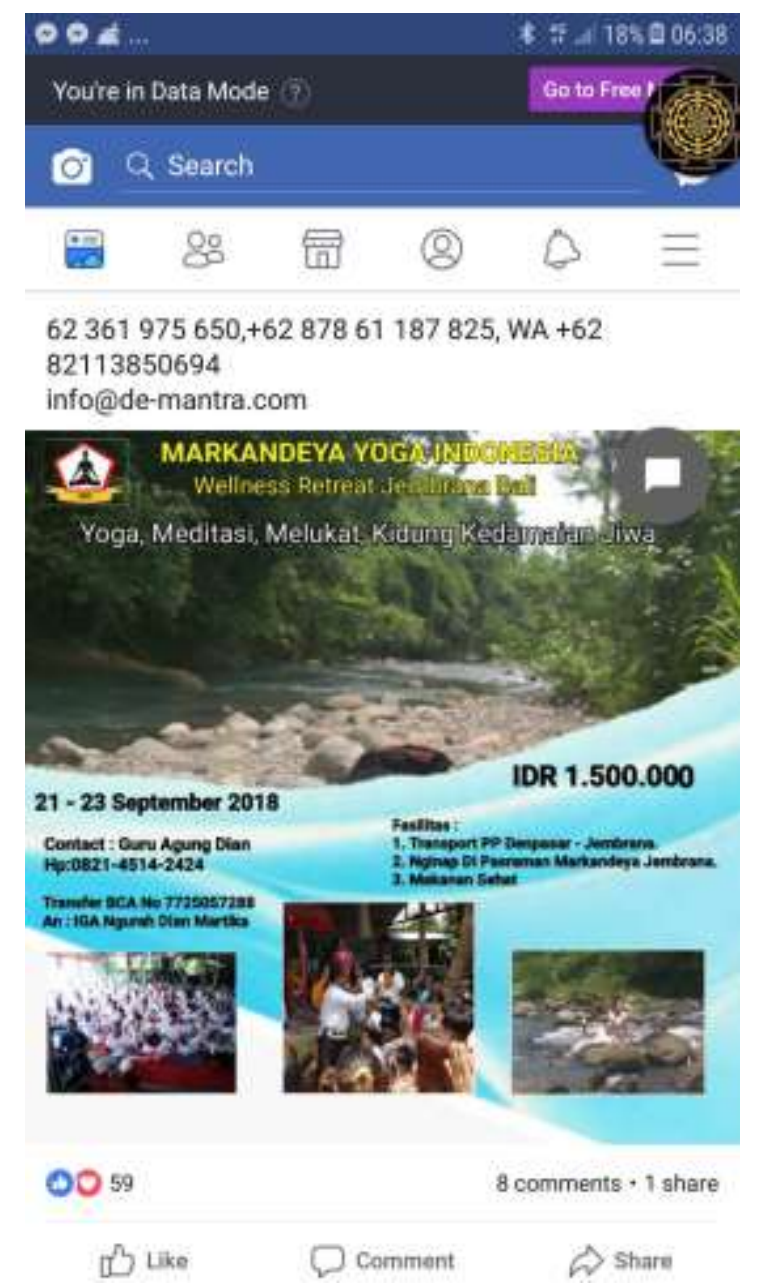

Gambar 1: Keunikan Yoga yang Ditawarkan Sumantra (Sutarya, 2018:35) Kesimpulan

Bali pada awalnya hanya menjadi tempat pariwisata yoga, tetapi belakangan potensi yoga lokal mendapatkan tempat dalam pariwisata yoga. Potensi pariwisata yoga dikembangkan berdasarkan keunikan yoga di Bali yang berdasarkan teks-teks kuno yang telah berkembang sejak masuknya Hindu ke Indonesia. Potensi keunikan tersebut adalah ritual, teknik pernapasan dan pelayanan guru-guru yoga lokal yang khas. Keunikan ini yang dikembangkan dalam pariwisata yoga di Bali.

Keunikan ini merupakan tingkat kepuasan yang paling besar bagi wisman. Karena itu, pengembangan produk yoga di Bali harus menjadikan keunikan ini menjadi augmented produk dari pariwisata yoga di Bali. Keunikan tersebut merupakan pembeda antara yoga di Bali dengan yoga-yoga lainnya di dunia. Pembeda adalah keunggulan produk dalam pemasaran pariwisata yang harus ditemukan pada setiap produk pariwisata. 
Daftar Pustaka

Acri, Andrea. 2013. Modern Hindu Intelectual and Ancient Texts: Reforming Saiva Yoga in Bali. Bijdragen tot de Taal, Land-en Volkenkunde.169: 68-103.

Lalonde, Angelique Maria Gabrielle. 2012. Embodying asana in All New Places: Transformational Ethics, Yoga Tourism and Sensual Awakening. (Dissertation). Canada: University of Victoria.

Ramstedt, Martin. 2008. Hindu Bonds at Work: Spiritual and Commercial Ties Between India and Bali. The Journal of Asian Studies. 67 (4): 114-118.

Rossin, Hanna. 2006. Striking a Poe. The Atlantic Monthly. 298 (5): 114-118.

Schiffman, Leon dan Leslie Lazar Kanuk. 2008. Perilaku Konsumen. PT. Index: Indonesia.

Sutarya, I Gede. 2016. Spiritual Healing dalam Pariwisata Bali: Analisis Tentang Keunikan, Pengembangan, dan Kontribusi terhadap Pariwisata. (Disertasi). Denpasar: Universitas Udayana.

Sutarya, I Gede. 2018. Keunggulan Kompetitif Guru Yoga Lokal dalam Pariwisata Spiritual di Bali (Hasil Penelitian). Denpasar: Institut Hindu Dharma Indonesia. 